\title{
Anomalous weather events in central Himalaya: real-world observations and some questions
}

\author{
K. S. Valdiya
}

The central sector of the Himalayan province is witnessing inordinately frequent incidences of extreme weather, unending cycles of prolonged droughts and very short spells of excessive rainfall over geographically limited areas, absence of 'April Showers' before the onset of summer monsoon, and delayed arrival of the Indian summer monsoon. Are these happenings related to merely the rise in atmospheric and surface temperatures due to global warming, or are they caused by the excess presence of biogenic carbon generated by rampant burning of agricultural residues and wastes, and uncontrolled forest fires? One would also like to know whether the western disturbances and/or the mid-latitude interactions have a role in these distressing developments. The simplistic answer that all these anomalous happenings are 'the combined effect of global warming enhanced by anthropogenic influences' is hardly convincing to the laymen who solicit answers to these questions from experts - in a language free from technical jargon.

Keywords: Biogenic carbon, cloudbursts, droughts, global warming, winter disturbances.

\section{Happenings in the last two decades}

As a witness to and belonging as I do to the community of helpless victims due to extreme events and erratic behaviour of weather, I write this article to elicit answers to the multiple questions I face from the alarmed people among whom I move in and around the central Himalaya (Figure 1) - answers in a language understandable by the common people. As a geologist studying tectonic turbulence and attendant hazards, I have been for over 55 years walking and driving across the mountainous terrains of Uttarakhand, India, $500 \mathrm{~km}$ long and $300 \mathrm{~km}$ across, encompassing tropical zone, subtropical zone, alpine zone and cold desert. The questions I am frequently asked relate to natural hazards, the strange behaviour of weather and the distressingly irregular changes in climate - the incidences of extreme weather events, the more frequent freak-weather phenomena, the distressingly prolonged droughts broken by brief spells of ravaging cloudbursts, the hailstorms that destroy with unfailing regularity the harvests of fruits, flowers, vegetables and cereals, the torturing cold storms during winters and the blinding smoky 'fog' that densely envelopes the plains right in front of the central sector of the Himalayan province.

\footnotetext{
K. S. Valdiya is in the Jawaharlal Nehru Centre for Advanced Scientific Research, Bengaluru 560 064, India.

e-mail:ksvaldiya@gmail.com
}

Also, the so-called 'April Showers' or pre-monsoon local rainfall that used to drench regularly the central Himalayan land practically every afternoon in April, May and early June, have almost ceased. As a consequence, springs and seepages have diminished discharges, streams and rivers have reduced water flow, summers have become drier and oppressively warmer, and wildfires have become uncontrollable all over. If there is any precipitation, it comes in the form of short showers accompanied by destructive hails.

The people ask why the 'April Showers' or premonsoon local rains have ceased.

The delay in the arrival in central Himalaya of summer southwest monsoon by two to three weeks (or even more) and its irregularity are spelling disasters for the farmers. According to Gadgil et al. ${ }^{\text {, }}$, equatorial Indian Ocean oscillation plays an important role in determining the rainfall in summer months, the sea-surface temperature of the western equatorial Indian Ocean sustaining the positive phase of the oscillation and thus bringing copious rainfall. According to some researchers, the early or late arrival of the Indian summer monsoon (ISM) is influenced by minor changes in the global circulation systems (G. B. Pant, pers. commun.). However, the delayed rains that occur are not uniform, either in space or in time. In the central Himalayan province, it is the stratiform clouds of low level within $2000 \mathrm{~m}$ above the ground surface that contribute $70 \%$ of total summer monsoon rainfall, the remaining $25 \%$ by the clouds between 2000 and $6000 \mathrm{~m}$ 
(ref. 2). In recent years, instead of not-so-thick stratiform clouds covering large areas and causing persistent rainfall and drizzles as in the past ${ }^{3}$, the clouds that gather now are convective having great vertical extent and smaller horizontal spread so that the rainfall is heavy, for shorter duration and over geographically limited areas. Why do the cloud layers - which used to darkly envelop vast regions uniformly, now break up into small patches? Why have the cloud layers become thinner? Why does unusually excessive rainfall occur for short spells over very limited geographic areas, with vast stretches of land remaining bereft of the bounty of clouds?

Rainfall events of 2012 and 2013 in Uttarakhand have been particularly very severe. During the short interval of 16-18 June 2013, the average rainfall all over the state was respectively, 71.7, 133.3 and $81 \mathrm{~mm}$, with several meteorological stations recording as high as $220 \mathrm{~mm}$ rainfall ${ }^{4}$. This is not to say that extreme rainfall events have happened only in recent decades. As a matter of fact, there were five very heavy rainstorm events in the period 1875-2010, the one during 28-30 September 1924 in Uttarkashi being the severest. However, the frequency of such severe happenings has increased-rather they have become quite common.

The usual scenario now in the whole of the Siwalik and the Lesser Himalayan sub-provinces is that clouds remain hung for over days or weeks on end without precipitation. And then they are pushed or blown northwards by swifter winds.

However, the pattern and trend of rainfall are very different in the narrow nearly $50-\mathrm{km}$ wide belt encompassing the steep southern flank of the formidable Great

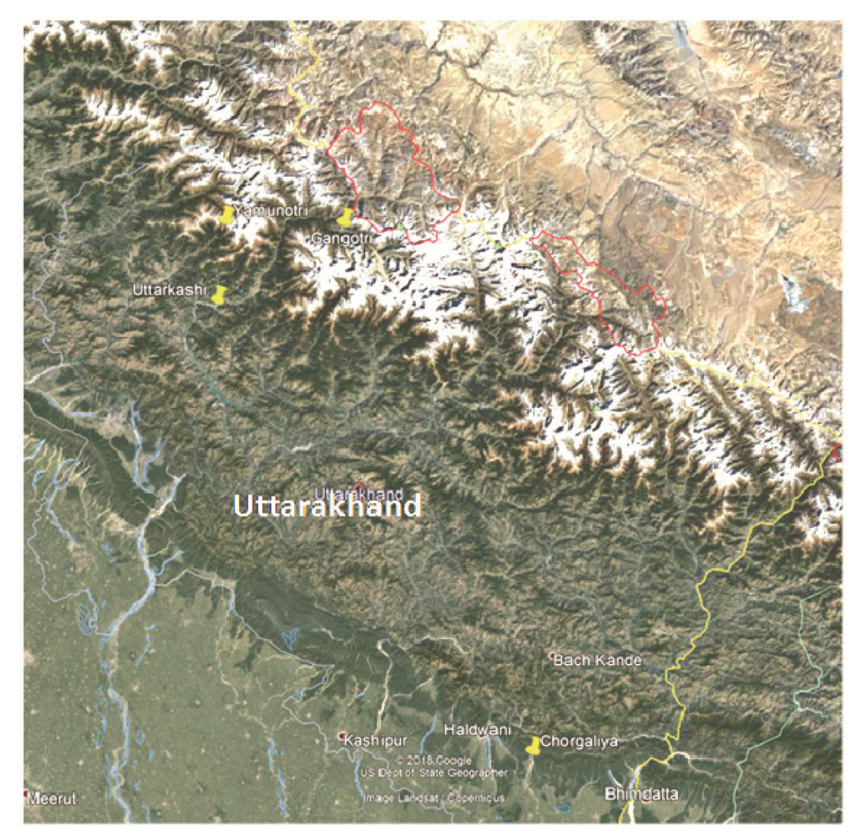

Figure 1. Satellite image of the central sector of the Himalaya and adjoining Indo-Gangetic Plains [source: Google Earth].
Himalaya, and the belt where the 2600-3000 m Lesser Himalayan ranges abruptly soar to the 6000-7600 $\mathrm{m}$ high ever-snowy Great Himalaya (Figure 2). The southern flank of the Great Himalaya is represented by a series of virtually wall-like high scarps. It is this narrow zone of sudden change of elevation of mountain ranges where the huddled-up, piled-up dense clouds precipitate - and precipitate excessively, inexorably and incessantly for prolonged periods in season and out of season. This has been going on for the last over 15-20 years. Not that it did not happen earlier. It did, and many many times all through the long past. But now it has become a regular phenomenon.

The melt water in the Great Himalayan realm contributing additional moisture, the 'orographic lifting' up on the steep to nearly vertical slopes produces convective clouds of large extent ${ }^{3}$ causing intense rainfall - the rainfall rate being in the range $200-1000 \mathrm{~mm} / \mathrm{h}$ (ref. 5) and $324 \mathrm{~mm} / \mathrm{h}$ at Chorabari glacier, Mandakini valley in mere $24 \mathrm{~h}$ in mid June 2013 (ref. 6). The Munsiari area on the southern slope of the Great Himalaya in northeastern Uttarakhand has been receiving - in recent years - the highest southwest summer rainfall anywhere in the state. Coincidentally, this is the part of the Himalaya which is also registering the highest seismicity anywhere in the entire Himalayan province - in terms of the number of earthquakes of the magnitude 2 to 5 -implying almost continual release of tectonic stresses, the rate of stress drop being low. Comprehensive analysis of the Tropical Rainfall Measuring Mission 3B 42 and APHRODITE databases demonstrates that the rainfall values are very high up to an elevation of $3100 \mathrm{~m}$ and then fall substantially above that level ${ }^{7}$. According to the findings of the India Meteorological Department, the 1000-2000 m elevation levels receive maximum summer rainfall and then there is a sudden jump in precipitation near 4000-5000 m (ref. 7).

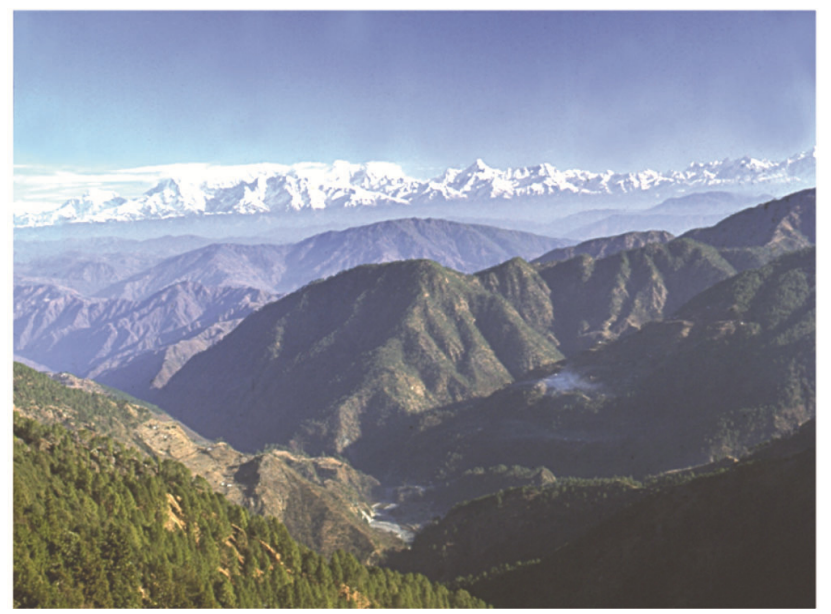

Figure 2. Photograph showing the Lesser Himalayan province, the narrow belt where the 2600-3000 m Lesser Himalayan ranges abruptly rise to the 6000-7500 $\mathrm{m}$ high formidable Great Himalaya, and the eversnowy Great Himalaya. 


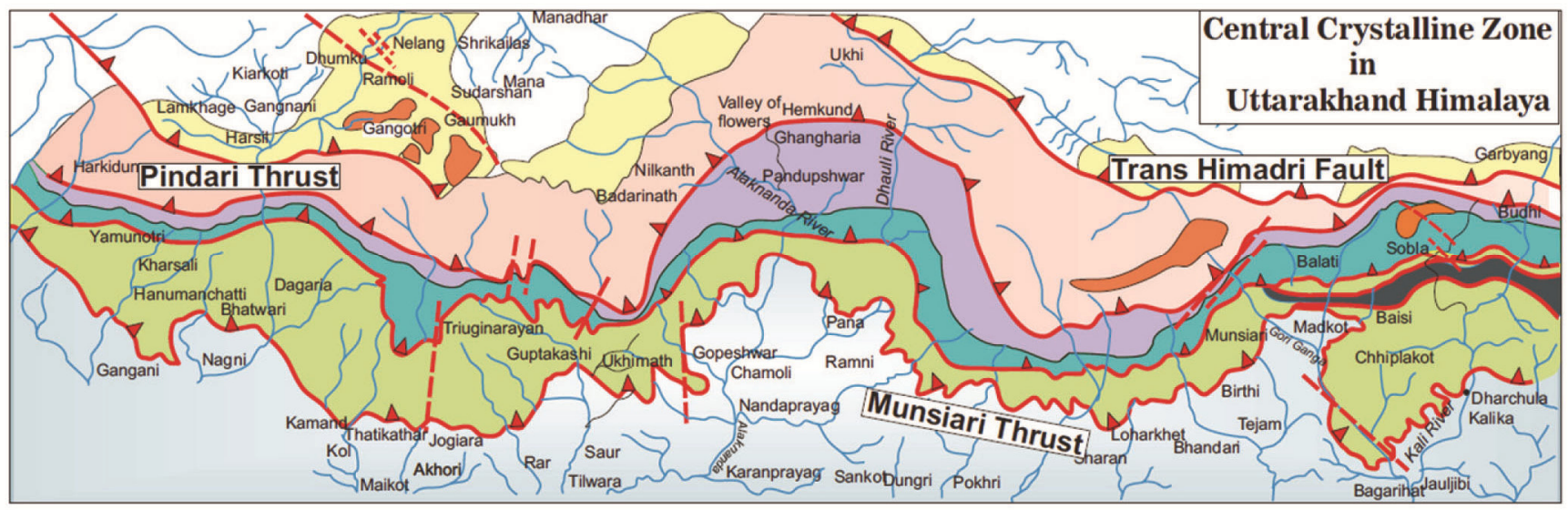

Figure 3. The narrow zone encompassing the steep southern flank of the ever-snowy Great Himalaya and adjoining Lesser Himalayan belt riven with a multiplicity of gently dipping long faults (called thrusts), most of which are very active and cause of frequent earthquakes. This zone is ravaged by excessive inexorable rainfall and uncontrolled mass movements on a large scale (from Valdiya et al. ${ }^{9}$ ).

Why do clouds hang over the Lesser Himalayan terrain for long periods without precipitating, but cause excessive incessant rainfall with or without snow only in the narrow zone where the mountain ranges abruptly soar from 2600-3000 to 6000-7500 m?

It may be mentioned that this narrow zone of the junction of the Lesser and Great Himalaya is riven with a multiplicity of gently northward-dipping long faults (called thrusts) stretching hundreds of kilometres laterally all along the expanse of the Himalaya ${ }^{8,9}$ (Figure 3 ). Then there are quite a few steep faults cutting across the trend of the Himalaya. Most of the thrusts and faults are very active, that is, movements continue to take place on them $^{10}$ as demonstrated by GPS measurements and frequent occurrence of small to moderate magnitude earthquakes ${ }^{11}$. Consequently, the Great Himalaya is rising at a faster rate. The rocks of this belt are highly broken, shattered and crushed. When the rains batter the vulnerable mountain slopes, the weakened rocks easily break loose, with resultant rockfalls, landslides, debris avalanches and related mass movements. This has been happening in the valleys of the rivers Kali, Eastern Dhauli, Gori, Western Dhauli, Alaknanda, Mandakini, Bhagirathi and Yamuna. The tragic events of 2009, 2010, 2012 and 2013 bear testimony to the enormity of the disasters that happened due to excessive rainfall and consequent landslides of gigantic proportion ${ }^{8}$.

The climatologists are unsure of the role of high orographic features on the intensification of monsoon rainfall $^{12}$, and some tend to repudiate geologists' contention that intensification of ISM is related to the high elevation of the Tibetan Plateau and adjoining High Himalaya. This carries the implication that the height of the Himalayan mountain barrier cannot be the cause of intensive rainfall. However, there is abundant and convincing evidence for a broad correspondence between high monsoon precipitation and faster rate of tectonic uplift and resultant accele- ration of erosion in the Himalaya, particularly in the Great Himalaya $^{13}$. The rapid uplift of the mountain in the period 6.8 and 0.8 million years respectively, initiated and strengthened ISM. It was in this period that the Himalaya acquired its marquee structural architecture and attained its tremendous height, even as the monsoon became active ${ }^{13}$. The Great Himalaya, as already stated, continues to rise at a rate faster than $5 \mathrm{~mm} / \mathrm{yr}$ (ref. 14) due to being squeezed between two very active faults the Main Central Thrust in the south and the TransHimadri Detachment Fault (South Tibetan Detachment Fault) in the north ${ }^{10}$ (Figure 3).

Interestingly, very similar excessive rains have been battering the west-facing flank of the $1600 \mathrm{~km}$ long Sahyadri Ranges that abruptly rise from the 40 to $120 \mathrm{~m}$ level of the coastal plains to form high mountain rampart $->2600 \mathrm{~m}$ in central Kerala to $>1500 \mathrm{~m}$ in central Maharashtra. Like the Himalayan province, the Sahyadri is also riven with faults and fractures trending NNWSSE. Since these ranges are not as high as the Himalayan barrier, the clouds cross over them and precipitate copiously to heavily on the eastern flank of the Sahyadri as well, causing havoc on both sides.

If it is not the immense height of the Great Himalaya, what else is causing intense and seemingly unending precipitation in the narrow belt? Is just the rise temperature of the atmosphere and of the earth's surface responsible for the aberrant pattern of rainfall, as some climatologists believe (G. B. Pant, pers. commun.)?

There is no denying that both the atmospheric and surface temperatures in the central sector of the Himalaya are rising as the following narrative will show. But then as a student of geological history of the Indian subcontinent, I know that rise and fall of temperature have been going on since the beginning of the history of the earth and the haital changes taking place time and again. 


\section{Atmospheric and surface warming}

Compared to $0.5^{\circ} \mathrm{C}$ rise in temperature during the last 50 to 60 years in Peninsular India, warming in the Himalayan province was $1^{\circ} \mathrm{C}$ (ref. 15). In the Alaknanda valley in Garhwal, the mean annual temperature increase was $0.15^{\circ} \mathrm{C}$ between 1960 and 2000, while in the Kashmir Valley the average temperature rise was $1.45^{\circ} \mathrm{C}$ in the period 1996-2006 (ref. 16). It may be emphasized that the temperature rise was more pronounced during winter season and least in the summer months ${ }^{3}$. Winter-time observations made during 1991-2015 over Northwestern Himalaya showed that in all the three belts - the Lesser Himalaya, the Great Himalaya, the Karakoram - overall warming was noticeable in all aspects - the maximum increased by $0.9^{\circ} \mathrm{C}$, the minimum by $0.19^{\circ} \mathrm{C}$ and the mean by $0.65^{\circ} \mathrm{C}$ in the period $1991-2015$ (ref. 17). The rise in mean temperature $\left(0.87^{\circ} \mathrm{C}\right)$ was highest in the Great Himalaya followed by Karakoram $\left(0.56^{\circ} \mathrm{C}\right)$, but the minimum temperature diminished in the Lesser Himalayan sub-province ${ }^{17}$.

Why is the Great Himalayan realm of perennial snow and glaciers hotting at a rate two times more than the rest of the Indian land mass of much lower elevation in lower latitudes?

There are tell-tale signs of the fast retreat of glaciers and shrinking snow cover in the Great Himalayan domain. For example, the Chaturangi Glacier that forms a branch of the Gangotri Glacier retreated $1172.57 \pm 38.3 \mathrm{~m}$ in just 27 years at the rate of $45.07 \pm 4.31 \mathrm{~m} / \mathrm{yr}$ in the period 1989-2016 (ref. 18), and the areal extent of the Chorabari Glacier from which the Mandakini River originates shrank $344 \pm 24 \mathrm{~m}$ in 50 years from 1962 to 2012 (refs $19,20)$, decreasing at the rate of $0.8 \% / \mathrm{yr}$ in the period 1976-2016 (ref. 21). The Milam Glacier in eastern Uttarakhand receded $480 \mathrm{~m}$ in just six years from 2004 to 2011 , even as 47 glacial melt-water ponds were formed ${ }^{19}$. The latest study of satellite images of 650 glaciers across the whole of the Himalayan province carried out by Maurer $^{22}$ showed that between 1975 and 2000, the glaciers lost ice at the rate of 10 inches per year, the rate doubling in the subsequent period 2000-2018 to 20 inches per year (ref. 23). The IRS LISS-III satellite imagery of the period 2000-2011 showed a different picture - of the 2018 glaciers studied, 1752 (86.8\%) had stable front, registering no change in the position of their snouts and areas of ablation, while $248(12.3 \%)$ retreated and 18 $(0.9 \%)$ glaciers made advancement of their snouts ${ }^{24}$. Earlier studies carried out at Grenoble University, France, also showed that the Karakoram glaciers gained at the rate of $0.11-0.22$ inches per year in the period 1999 and 2008 (refs 25, 26). Yet another study of the snow cover in Northwest Himalaya encompassing the basins of the Ganga, Satluj, Chenab and Sindhu rivers showed that the snow cover increased, particularly in the period 2004-14 (ref. 27).
If the temperature is rising all over the Great Himalaya, why are there contradictory observations - glaciers retreating, retaining stable fronts and buildingadvancing - when overall warming in the NW Himalaya is noticed in all respects?

\section{Questions that farmers and foresters ask}

Wherever and whenever I give a talk, I face a volley of questions from farmers, horticulturists and foresters regarding the problems they are facing.

The duration of ripening of wheat and rice crops has decreased and production of grains changed. According to the farmers, while the yield of winter maize has gone $u^{28}$, wheat production has decreased up to $36-50 \%$ in the plains of Uttar Pradesh ${ }^{29,30}$, although it has increased in Himachal Pradesh $-3.6-7.3 \%$ wheat, $7.6-20.8 \%$ rice and $1.3-3.5 \%$ soybean $^{28}$.

The apple plantations are no more economically viable in Himachal Pradesh ${ }^{28}$ as in Uttarakhand, where the yield has gone down and growers are forced to relocate plantations to higher altitudes at back-breaking costs and with insurmountable problems.

Rhododendron arboreum in the reserved forests at four different localities, viz. Syahidevi, Binsar, Jalna and Mukteshwar in disparate ranges within the Almora district witnessed a flowering intensity of $61-86 \%$ in early February 2009, 43-60\% in late February to early March 2010, and 41-53\% in early March 2011 (ref. 31). This finding is based on real-time observations in the interval 2009-11 and a study of herbarium records for the period 1893-2003. Understandably, this is happening due to delayed seed production and attendant nutrient cycling. The high-altitude plants like Pinus wallichiana and Solvia anthemifolia that are common in the Nandadevi Biosphere have migrated further upwards ${ }^{32}$.

The fruit kaaphal of the tree Myrica esculenta in the oak forests is now ripening as early as mid-December to early January instead of peak summer May and June.

Needless to state, some of these developments have disrupted the food supply system of wildlife.

Is it only the rise of temperature that is bringing about these changes in the plant kingdom? Is not the particulate matter dispersed in the air and fallen on trees and thus clogging the stromata of leaves responsible for inhibiting their growth or changing their metabolism? This question arises in the context of great disparity of temperature variation in the different latitudinal belts (sub-provinces) of the Himalaya, as already adumbrated.

\section{Plentiful carbon particles in the lower atmosphere}

A multi-institutional and multi-instrument campaign over the Himalaya and Indo-Gangetic Plains involving intense 
observations at the nearly $1958 \mathrm{~m}$ high Manora Peak near Nainital, Uttarakhand for 65 months from August 2009 to December 2014 revealed spring-time (April to early June) enhancement of aerosol black carbon mass concentration ( $\sim 100 \mathrm{ng} / \mathrm{m}^{3}$; and of spectral aerosol optical depth) with lowest during the rainy season in August-September ${ }^{33}$. There is a clear build-up of black carbon aerosol from December to June and another peak of enhancement $\left(\sim 70 \mathrm{ng} / \mathrm{m}^{3}\right)$ in October, which disappears in December ${ }^{33}$. There is significant inter-annual variability, with springtime (April-June) enhancement of aerosol carbon mass concentration. The vertical extent of elevated aerosol layers ranges from 5000 to $7000 \mathrm{~m}$ amsl (ref. 33).

The lower 2000-3000 m layer of the atmosphere over the sprawling Indo-Gangetic Plains and the adjoining belts of the Himalayan province is charged heavily with particulate matter such as dust, ash, salts, sulphates and carbon, in addition to greenhouse gases. There are two types of carbon-black carbon generated by burning of fossil fuels and brown carbon produced by burning of biomass of the agricultural residues and wastes, and of forests. Small in size, the carbon particles remain in the air for quite a few weeks ${ }^{34}$.

Ever since the farmers took in a big way to mechanized harvesting, there is greater burning of paddy and wheat stubbles and other agricultural residues following kharif and rabi harvests. In springs and summers - which have become uncommonly drier now - the forests all over Uttarakhand and Himachal Pradesh are inexorably afire until heavy rains put an end to the burning. One can imagine the magnitude of organic carbon in the air when one realizes that in a short period, mid-February to midJune 2018, nearly 3900 ha of forest in Uttarakhand were afire, and in the last 19 years over 44,500 ha of forests of this state burned with uncontrollable fury of wildfire ${ }^{35}$. The months of April-May 2016 saw practically the whole of Uttarakhand forests burning without check and generating $\mathrm{CO}_{2}, \mathrm{NO}_{2}$, ozone and aerosol of optical depth, etc. which reached an alarming level in the altitudes 2000$3000 \mathrm{~m}$ above the surface - the amount of CO double of the mean background values and $\mathrm{NO}_{2}$ three times more than the normal ${ }^{36}$.

Consequently, the lower atmosphere over the IndoGangetic Plains and the Lesser Himalaya is densely charged with very large amounts of biogenic carbonalmost 1.5 time higher than normal annual average concentration $^{33}$. Making the atmosphere very hazy, the biogenic carbon appears brown from aircraft ${ }^{37}$. The haze extends from about November to April ${ }^{38}$. Nowadays, it extends quite beyond April.

\section{Behaviour of biogenic carbon}

Compared to the inorganic black carbon, biogenic brown carbon has significantly different absorption properties in that it absorbs strongly at the blue and ultraviolet regions and very little absorption in the visible ${ }^{34,39,40}$. It is this property that inhibits coalescence of cloud drops to form rain drops in the lower atmosphere where the aerosol content is phenomenally increasing to alarmingly high levels over the Indo-Gangetic Plains and the adjoining belts of the Himalayan province.

It is known that aerosols provide the nuclei for cloud drops (without aerosols cloud-drop formation will require relative humidity in excess of $150 \%$ ). 'Recent studies have shown that anthropogenic haze produces copious amounts of smaller drops in convective clouds, thus suppressing precipitation over polluted areas ${ }^{41}$.' Therefore, 'An increase in the concentration of aerosol would result in an increase in the number of cloud droplets, which in turn can increase its cloud albedo... . This increases the cloud lifetime and inhibits precipitation ${ }^{34}$.'

Importantly, relevant results have come from studies on the consequences of forest fires in the Amazon Basin in South America. According to Andreae et al. ${ }^{42}$, 'heavy smoke from forest fires in the Amazon was observed to reduce cloud droplet size and so delay the onset of precipitation from $1.5 \mathrm{~km}$ above the cloud base in pristine cloud to more than $5 \mathrm{~km}$ in polluted clouds.' In other words, the smoky air shows substantially reduced droplet size, compared to that of similar clouds in cleaner air. Therefore, in a high-concentration aerosol atmosphere, although the carbon particles do nucleate cloud droplets, there is predominance of small cloud droplets that are too slow to coalesce and precipitate, and therefore remain in the air and create rainless condition. The situation of vigorous convection allows updrafts - upward movement of the clouds to the high and super-cooled regions, with resultant ice precipitation, large hail and intense thunderstorms. Thus there would be 'isolated intense showers and thunderstorms'.

Simultaneous observation of aerosols, cloud condensation nuclei and cloud droplet number concentration over the Ganga Plains during ISM shows very high-more than $1000 / \mathrm{cm}^{3}$ - cloud condensation nuclei at elevated layers extending up to $6000 \mathrm{~m}$ and the cloud droplet number concentration increases with increase in the aerosol number concentration ${ }^{43}$. These observations thus demonstrate that pollution increases the warm rain depth and delays its initiation ${ }^{43,44}$.

I wish to know from climatologists whether these deductions or surmises are plausible explanation for the situation we see in the central sector of the Himalayan province and the adjacent plains? The reason I am asking this question is the assertion in the following observations of Srinivasan and Gadgil ${ }^{37}$ : 'It is clear that the reliability of the projection of a decrease in rainfall over this region (Indo-Gangetic Plain) due to haze on the basis of simulation by this model is suspect' ... 'Thus we expect natural aerosols to have a greater impact on the monsoon than the anthropogenic aerosols.' 
The agricultural wastes and residues are burned by farmers and more than $90 \%$ forest fires are undeniably man-made.

Judging from the deductions of a majority of climatologists and my own observations as a field geologist, I surmise that the presence of excessive biogenic carbon in the lower atmosphere 2000-3000 m amsl over the IndoGangetic Plains and adjoining belts of the Himalayan province is responsible for the inexorable cycle of prolonged periods of droughts and short spells of excessive rainfall. The short spells of heavy rains are often accompanied by hails and thunderstorms over geographically limited areas, whenever and wherever there is upward movement of air currents (updraft). Perhaps the delayed arrival in the central sector of the Himalaya by as much as two to three weeks of ISM and the non-uniformity of rainfall in space as well as time are also related to the same cause.

Am I right in my surmise, and in my speculation?

\section{Role of winter westerlies}

An unusual development in early September 2014 in the Kashmir Himalaya left me wondering 'whether the intervention of proactive winter disturbances embedded in large-scale westerlies in ISM is responsible for the erratic weather or freak events of excessive rainfall'. According to Pant et $a l .{ }^{3}$, 'when monsoon currents get coupled with the Western Disturbances' and 'local weather systems develop due to orography or convection', there is 'enhanced and prolonged rainfall activity'.

Is this situation the sole cause of erratic rainfall witnessed nowadays?

In the interval 2-5 September 2014, the western disturbances in the form of a cyclonic circulation or trough in the mid-troposphere remained practically stable over North Pakistan and adjoining Jammu \& Kashmir, India, from 2 to 5 September 2014. The interaction of eastwardadvancing deep trough in the westerlies with the westward-moving ISM when Kachchh and Saurashtra in Gujarat, and northwestern and central India were in the grip of a low-pressure system in the same period, caused excessive rainfall of the order of 148-309 $\mathrm{mm}$ that broke all records ${ }^{45,46}$.

Originating in the Mediterranean Sea in the Far West, the western disturbances sweep across dry West Asian lands, and picking up moisture from the Caspian Sea and the Red Sea, they cross the Hindukush Ranges, reaching Northwest Himalaya. In the passage over the dry land of Iran and Afghanistan, they develop depressions and hence are called 'western disturbances'. In the winter months of December, January and February, almost onethird of the annual precipitation in NW Himalaya extending southeast up to western Uttarakhand is received from the western disturbances ${ }^{47}$. A part of the upper-level jets of the western disturbances moves southwards and provides rainfall in western India ${ }^{48}$.

The southeastward geographic reach of the winter westerlies has diminished in recent decades. Until about the early nineties of the last century, the eastern part of Uttarakhand and adjoining western Nepal used to get ample snowfall and rainfall during winter. Now the winter westerlies commonly do not move beyond the Ganga (Alaknanda) Basin in western Uttarakhand. However, the period of activities of the winter westerlies has extended beyond February, in the Great Himalayan realm, and snowfall can occur in April or even in May. Although there is a decline in the frequency of cold waves, there is no let up, no lessening of their severity in the Lesser Himalaya.

What indeed is the role of winter disturbances in the climate aberration witnessed in the central Himalaya needs to be answered.

1. Gadgil, S., Francis, P. A. and Vinayachandran, P. N., Summer monsoon of 2019: Understanding the performance so far and speculating about the rest of the season. Curr. Sci., 2019, 117, 783793.

2. Singh, N. et al., Variation in the cloud-based height over central Himalaya during GVAX: Association with the monsoon rainfall. Curr. Sci., 2016, 111, 109-116.

3. Pant, G. B., Kumar, P. P., Revadekar, J. V. and Singh, N., Climate Change in the Himalayas, Springer, Cham, 2018, p. 145.

4. Kaur, S. and Gupta, P. K., Devastating rainstorm of June 2013 in Uttarakhand. Mausam, 2017, 68, 633-642.

5. Joshi, V. and Kumar, K., Extreme rainfall events and associated natural hazards in Alaknanda valley, Indian Himalayan region. $J$. Met. Sci., 2006, 3, 228-236.

6. Dubey, C. S., Shukla, D. P., Ningreichon, A. S. and Usham, A. L., Orographic control of the Kedarnath disaster. Curr. Sci., 2013, 105, 1474-1476.

7. Banerjee, A., Dimri, A. P. and Kumar, K., Rainfall over the Himalayan foothill region: Present and future. J. Earth System Science, 2020.

8. Valdiya, K. S., Excessive rains and landslides in Main Central Thrust Zone and the wrath of rivers. J. Indian Geol. Congress, 2014, 6, 27-34.

9. Valdiya, K. S., Pal, S. K., Tara Chandra, Bhakuni, S. S. and Upadhyay, R. C., Tectonic and lithological characterization of Himadri (Great Himalaya) between Kali and Yamuna rivers, Central Himalaya. Himalayan Geol., 1999, 20, 1-17.

10. Valdiya, K. S., Reactivation of terrane-defining thrusts in central sector of Himalaya. Curr. Sci., 2001, 81, 1418-1431.

11. Pant, C. C., Pathak, V. and Darmwal, G. S., Seismotectonic investigation in a part of central seismic gap, Uttarakhand. Zeit. Gastroenterol., 2013, 58, 59-79.

12. Chakraborty, A., Nanjundiah, R. S. and Srinivasan, J., Role of Asian and African orography in Indian Summer Monsoon. Geophys. Res. Lett., 2002, 29, 1-4.

13. Valdiya, K. S., Rising Himalaya: Advent and intensification of monsoon. Curr. Sci., 1999, 76, 514-524.

14. Valdiya, K. S. and Sanwal, J., Neotectonism in the Indian Subcontinent: Landscape Evolution, Elsevier, Amsterdam, 2017, p. 435 .

15. Srinivasan, J., Hottest decade: Early warning or false alarm? Curr. Sci., 2006, 90, 273-274. 
16. Kumar, K., Joshi, S. and Joshi, V., Climate variability, vulnerability and coping mechanism in Alaknanda catchment, central Himalaya, India. Ambio, 2008, 37, 286-291.

17. Negi, H. S., Kanda, N., Shekhar, M. S. and Ganju, A., Recent wintertime climate variability over the northwest Himalayan cryosphere. Curr. Sci., 2018, 114, 760-770.

18. Bisht, H., Rani, M., Kumar, K., Sah, S. and Arya, P. C., Retreating rate of Chaturangi Glacier, Garhwal Himalaya, India derived from kinematic GPS survey and satellite data. Curr. Sci., 2019, 116, 204-311.

19. Govindh Raj, K. B., Vinod Kumar, K., Mishra, R. and Mukhar, M. A., Remote sensing based assessment of glacial lakes growth in Milam Glacier, Goriganga basin, Kumaun Himalaya. J. Geol. Soc. India, 2014, 83, 385-392.

20. Mehta, M., Dhobal, D. P., Kesarwani, K., Pratap, B., Kumar, A. and Verma, A., Monitoring of glacier changes and response time in Chorabari Glacier, India. Curr. Sci., 2014, 107, 281-289.

21. Bandyopadhyay, D., Singh, G. and Birajdar, F., Remote sensing analysis of changes in Chorabari Glacier, Central Himalaya, India. Curr. Sci., 2018, 114, 771-782.

22. Maurer, J. M., Columbia University, USA.

23. Sengupta, The Times of India, 21 June 2019.

24. Bahuguna, I. M. et al., Are the Himalayan glaciers retreating? Curr. Sci., 2014, 106, 1008-1013.

25. The Hindu, 12 April 2012.

26. Nature Geoscience, The Hindu, 12 April 2012.

27. Rathore, B. P. et al., Trends of snow cover in western and westcentral Himalayas during 2004-2014. Curr. Sci., 2018, 114, 800 809.

28. Rana, R. S., Kalia Vaibhav, R., Pathania, R. and Singh, K. K. Managing impacts of extreme weather events on crop productivity in mountain agriculture. Mausam, 2016, 223-232.

29. Jenifer, B. and Ramanathan, V., The Hindu, November 2014.

30. Abdul Haris, A. V., Biswas, S., Chhabra, V., Elanchezian, R. and Bhatt, B. P., Impact of climate change wheat and winter maize over a sub-humid climate enunciation. Curr. Sci., 2013, 104, 206214.

31. Gaira, K. S., Rawal, R. S., Rawat, B. and Bhatt, I. D., Impact of climate change on the flowering of Rhododendion arboreum in Himalaya, India. Curr. Sci., 2014, 106, 1735-1738.

32. Rawat, D. S., Uphill journey of plants in the Himalaya. Curr. Sci., 2010, 99, 1644-1645.

33. Kompalli, S. K., Babu, S. S., Bharatan, L. N. and Krishnamoorthy, K., Spring-time enhancement in aerosol burden over a highaltitude location in western trans-Himalaya: results from longterm observations. Curr. Sci., 2016, 111, 117-131.
34. Satheesh, S. K., Atmospheric chemistry and climate. Curr. Sci., 2012, 102, 426-439.

35. Upadhyay, V., Times of India, 23 April 2019.

36. Madhav Haridas, M. K., Rao, P. V. N., Sreenivas Rao, K. and Sudhakar, P., Studies of forest fire induced changes in the atmosphere over Uttarakhand, India, using space-based observations and model simulation. Curr. Sci., 2018, 114, 2504-2512.

37. Srinivasan, J. and Gadgil, S., Asian Brown Cloud - fact and fantasy. Curr. Sci., 2002, 83, 586-592.

38. Ramanathan, V., Crutzon, P. J., Mitra, A. P. and Sikka, D., The Indian Ocean experiment and the Asian Brown cloud. Curr. Sci., 2002, 83, 947-955.

39. Satheesh, S. K. and Srinivasan, J., A method to estimate aerosol radiative forcing from spectral optical depth. J. Atmos. Sci., 2006, 63, 1082-1092.

40. Lelieveld, J. et al., The Indian Ocean experiment: Widespread air pollution from South and Southeast Asia. Science, 2001, 291, 1031-1036.

41. Rosenfeld, D., Suppression of rain and snow by urban and industrial air pollution. Science, 2000, 287, 1793-1796.

42. Andreae, M. O., Rosenfeld, D., Artaxo, P., Costa, A. A., Frank, G. P., Longo, K. M. and Silva-Dias, M. A. F., Science, 2004, 303, 1337-1342.

43. Kulkarni, J. R. et al., The Cloud-Aerosol Interaction and Precipitation Enhancement Experiment (CAIPEEX): overview and preliminary results. Curr. Sci., 2012, 102, 413-425.

44. Rosenfeld, D., Flood or drought: how aerosol affects precipitation? Science, 2008, 321, 1309-1313.

45. Yadav, B. P., Kumar, N. and Lotus, S., Synoptic and climatological aspects of extreme rainfall over western Himalaya towards the end of 2014 SW monsoon season. Mausam, 2017, 68, 597-606.

46. Ray, K., Bhan, S. C. and Bandopadhyay, B. K., The catastrophe over Jammu and Kashmir in September 2014: a meteorological observation analysis. Curr. Sci., 2015, 109, 580-591.

47. Dimri, A. P. and Chevuturi, A., Model sensitivity study for western disturbances over the Himalaya. Metereol. Atmos. Phys., 2013; doi:10.1007/s 00703-013-0302-4.

48. Dimri, A. P., Yasunari, T., Kotlia, B. S., Mohanty, U. C. and Sikka, D. R., Earth Sci. Rev., 2016, 163, 297-322.

Received 21 January 2020; accepted 31 March 2020

doi: $10.18520 / \mathrm{cs} / \mathrm{v} 119 / \mathrm{i} 1 / 19-25$ 